\title{
Análisis descriptivo de las fotografías de la guerra de Cuba en la prensa española de 1898: atributos documentales, codificación periodística y maquetación
}

Descriptive analysis of the photographs of the Cuban war in the Spanish press in 1898: documentary attributes, codification and layout

\author{
Joaquín B. López del Ramo \\ Universidad Rey Juan Carlos, \\ C/Paseo del Molino S/N, 28943 Fuenlabrada (Madrid), joaquin.lopezdelramo@urjc.es
}

\begin{abstract}
Resumen
Este trabajo tiene por objeto analizar los atributos documentales y periodísticos de las fotografías sobre la guerra Cuba de 1898 publicadas en las revistas La llustración Española y Americana, Blanco y Negro y Nuevo Mundo. Los resultados obtenidos sobre una muestra de 345 imágenes indican una escasa identificación biográfica y temporal. Predominan los planos generales y el estatismo, no se muestran acciones de guerra y las fotos se publican en pequeño tamaño. Las principales conclusiones del trabajo son: a) poca transparencia informativa y abuso de fotos de archivo; b) visión distante y artificiosa de la guerra, nada cruenta, salvo el episodio de la repatriación de los vencidos; y c) las fotografías desempeñan un papel de simple ilustración supeditada al texto.
\end{abstract}

Palabras clave: Guerra de Cuba. Fotoperiodismo. Documentación gráfica. Revistas gráficas. Análisis de contenido.

\section{Introducción}

La denominada Guerra de los Diez Años (18681878) y su consecuente, la Guerra de la Independencia Cubana, iniciada en febrero de 1895, culminaron en el enfrentamiento hispanonorteamericano de 1898, que supuso el fin del viejo imperio colonial y marcó en muchos aspectos el devenir de nuestro país. Los medios informativos de entonces dieron un protagonismo esencial a esta contienda, en la que con respecto a las precedentes existía un elemento nuevo y de enorme potencial informativo: la fotografía. La irrupción de la imagen fotográfica en la prensa a finales del siglo XIX, primero en las revistas gráficas y más tarde en los periódicos diarios, como describen Martín Aguado y Armentia (1995, pp. 189-190), abrió la posibilidad de que

\begin{abstract}
The aim of this paper is to present the documentary and journalistic attributes of photographs of the 1898 Cuba war published in three Spanish magazines of that epoch: La Ilustración Española y Americana, Blanco y Negro, and Nuevo Mundo. Results obtained on a 345 photographs sample show an insufficient biographical and temporal identification. General shots and static figures prevail, there are no war actions at all, and pictures have a small size. Main conclusions of this analysis are: a) There is a scant informative transparency, and an excessive use of archive photographs. b) There is a very distant and artificial vision of war, not cruel, except for the repatriation of the defeated episode. c) Photographs have a simple illustrative task.
\end{abstract}

Keywords: War of de Cuba. Photojournalism. Graphic documentation. Graphic magazines. Content analysis.

los lectores pudieran acceder a testimonios gráficos de la guerra, lo que, aún con muchas limitaciones, marcaba una nueva época.

Teniendo en cuenta lo anterior y el hecho, como remarca Sousa (2003, p.43), que la guerra fue un tema privilegiado en el nacimiento del fotoperiodismo, sumado a la importancia histórica e informativa que en concreto tuvo el desastre bélico de Cuba de 1898 en nuestro país, son los factores que ha servido de motivación esencial para este trabajo, cuyos principales objetivos son:

- Establecer la autoría de las fotos, su procedencia y origen geográfico.

- Identificar y describir a los protagonistas de las fotografías, sus roles, datos geopolíticos, gestualidad o expresividad y rasgos escenográficos que aparecen representados. 
- Evaluar el grado de proximidad de las fotografías a las acciones de guerra específicas a las que sirven de referente, a través del estudio de sus atributos espacio-temporales.

- Inferir los rasgos de interés periodístico y los valores expresivos que presentan las fotografías examinadas; en suma: qué visión general de la guerra ofrecen estas imágenes al lector.

- Determinar las características básicas de la maquetación de las fotografías en las páginas periodísticas donde fueron publicadas, como factor definitorio de su importancia informativa.

\section{Metodología}

La fotografía es una representación icónica de la realidad que en su uso periodístico posee un mensaje informativo, aunque también pueda cumplir funciones documentales, estéticas 0 simbólicas. Como portadora de tal mensaje, la fotografía periodística puede ser objeto de análisis de contenido. Desde esta premisa abordamos el estudio de las imágenes fotográficas publicadas durante la guerra hispanonorteamericana de Cuba de 1898 en las principales revistas gráficas de la época: Blanco y Negro, La Ilustración Española y Americana y Nuevo Mundo. Los límites temporales están comprendidos entre los meses de abril y septiembre de 1898, lapso que abarca desde la declaración de guerra por parte de Estados Unidos hasta la repatriación de los soldados españoles tras la capitulación española.

Consideramos como unidad de análisis cada una de las fotografías publicadas en las revistas de referencia sobre el conflicto bélico aludido, ya fueran obtenidas directamente en el campo de combate o en la retaguardia, bien reflejen acciones de guerra, preparativos, hechos consecuentes o relacionados. Ha sido analizada la práctica totalidad de fotografías publicadas durante el periodo antes mencionado referentes a la guerra de Cuba: 73 imágenes de La llustración Española y Americana, 139 de Blanco y Negro, y 133 del semanario Nuevo Mundo.

Se realizó una ficha de análisis para registrar los datos de cada unidad fotográfica, compuesta por tres grupos de indicadores que reflejan los atributos documentales básicos de la imagen, la codificación a través de las técnicas de expresividad fotográfica y el tratamiento en página 0 maquetación. Estos indicadores fueron seleccionados teniendo en cuenta las características específicas de la fotografía informativa de la época a la que pertenecen, según los fundamentos teóricos de los trabajos sobre esta materia publicados por Félix del Valle (1999), Alon- so Erusquin (1995) y Vilches (1987). La ficha de análisis consta de los siguientes campos:

a) Atributos documentales

- Autor: identidad y procedencia.

- Fecha de publicación.

- Identificación espacio-temporal.

- Actantes

- Geopolítica de los actores.

- Rol del actor.

- Presencia de víctimas o heridos.

- Registro de acciones de guerra

b) Codificación fotográfica:

- Encuadre: plano general, medio y corto.

- Género: retrato / paisajismo.

- Acción-estatismo.

- Gestualidad de los actantes.

- Escenografía: entorno ambiente, vestuario.

c) Maquetación:

- Tamaño: en columnas.

- Presencia de pie de foto.

- Presencia de otros gráficos.

Siguiendo a Bardin (2002, p. 28-29), se ha efectuado un análisis categorial, dirigido a clasificar y enumerar por frecuencia de presencia o ausencia los ítems de contenido significativos, en este caso los valores de los indicadores; y un análisis estructural, para establecer pautas de asociación, equivalencia o exclusión entre los mismos. Esto nos permite inferir datos relevantes respecto a los objetivos del estudio

\section{Resultados}

3.1. Análisis categorial: frecuencia de ítems de contenido

\section{A) Atributos documentales}

\section{Autor: identidad y procedencia}

Se observa una tendencia desigual respecto a la identificación del autor. En La Ilustración Española y Americana se identifica la fuente en 48 de las 73 fotografías. De las 139 fotografías publicadas en Blanco y Negro, sólo se explicita el autor o la fuente en 72, mientras que únicamente 36 de las 133 imágenes publicadas en Nuevo Mundo poseen dicha identificación. El desglose por número de fotos, procedencia 
geográfica y medio de publicación está cuantificado en la Tabla I.

\begin{tabular}{|c|c|c|c|c|}
\hline \multirow[t]{2}{*}{ Autor/Fuente } & \multirow[t]{2}{*}{ Origen } & \multicolumn{3}{|c|}{ Fotografías por autor } \\
\hline & & $\begin{array}{c}\text { Blanco } \\
\text { y Negro }\end{array}$ & $\begin{array}{c}\text { La } \\
\text { Ilustración }\end{array}$ & $\begin{array}{l}\text { Nuevo } \\
\text { Mundo }\end{array}$ \\
\hline C. Franzén & Madrid & 25 & 2 & \\
\hline Pérez Argemí & Cuba & & 24 & \\
\hline Lebrón & Cádiz & 10 & 6 & \\
\hline $\begin{array}{l}\text { Víctor L. } \\
\text { Rioboo }\end{array}$ & Coruña & & 14 & 4 \\
\hline Veiga & Vigo & 7 & & 10 \\
\hline Ferrer y Creus & Cuba & 8 & & \\
\hline $\begin{array}{l}\text { Black } \\
\text { and White }\end{array}$ & EEUU & 6 & & \\
\hline $\begin{array}{l}\text { Collier's } \\
\text { Weekly }\end{array}$ & EEUU & 5 & & \\
\hline Teijeiro & Coruña & 3 & & \\
\hline C. Castellón & Cartagena & 3 & & \\
\hline Amador & Madrid & & & 3 \\
\hline Baeza & Madrid & & & 3 \\
\hline Ángel & Cádiz & & & 3 \\
\hline Valenzuela & Santander & & & 3 \\
\hline José Bueno & Cuba & & 3 & \\
\hline Cepillo & Cádiz & 2 & & \\
\hline Urtasun & Santander & & & 2 \\
\hline \multicolumn{5}{|c|}{$\begin{array}{l}\text { Autores con } 1 \text { fotografía identificada: en Blanco y Negro, P. } \\
\text { Quintana (Santander), Campo Moreno (Madrid), Echegaray } \\
\text { (Madrid) y M. Cantos (Alicante); en La llustración Española y } \\
\text { Americana, José Balbá (Mallorca), J. Fornells (Barcelona), } \\
\text { Fernando Deba, J.Mon y Valentín; y en Nuevo Mundo: Debas y } \\
\text { Estudio Fotográfico. }\end{array}$} \\
\hline
\end{tabular}

Tabla I. Número de fotos por autor identificado, procedencia y publicación

Entre los autores con más relevancia se encuentra Christian Franzén, retratista y fotógrafo de la Casa Real, señalado como prolífico colaborador en prensa gráfica de la época por Rodríguez Merchán y Gómez (2003, p.37). Otro de los nombres destacados es el de Pérez Argemí, prestigioso autor de Santiago de Cuba y corresponsal de prensa durante la Guerra de Independencia cubana previa a la contienda con Estados Unidos, al cual se refieren Tusell, Acosta y Uz (2003, p.54). Asimismo, destacan los gallegos Rioboo y Veiga, autores de las fotografías que captan la llegada de las tropas repatriadas. Un aspecto curioso es la inserción en Blanco y $\mathrm{Ne}$ gro de varias fotografías de autores norteamericanos no identificados, indicándose, eso sí, los nombres de la fuente donde están obtenidas: las revistas Black and White y Collier's Weekly. A ellas hay que añadir otras tomas del ejército americano aparecidas en La llustración Española y Americana, aunque esta vez sin ninguna identificación de fuente.

\section{Fechas de publicación}

Las tres revistas analizadas publicaron fotografías alusivas a la guerra de Cuba de forma continuada durante el periodo temporal que abarcó el conflicto, con puntuales excepciones en las que las informaciones fueron textuales o sólo se emplearon grabados. Blanco y Negro fue la cabecera que más fotografías reprodujo y más regularmente; en el caso de La llustración Española y Americana y Nuevo Mundo la regularidad fue menor, decayendo durante el mes de agosto de 1898, una vez producida la rendición española, para volver a aumentar en septiembre con la llegada de los primeros repatriados.

\section{Atributos espacio-temporales}

Tanto en La Ilustración Española y Americana como en Blanco y Negro la mayor parte de las fotografías tiene identificado el lugar donde fueron captadas: el $73 \%$ (102 de 139) en el primer caso, y el $76 \%$ (59 de 73 ) en el segundo. En la revista Nuevo Mundo este dato se explicita sólo en un $49 \%$ de las fotos (65 de 133). Hay que señalar, no obstante, que en muchas de las imágenes sin identificación de este atributo, o bien no es relevante (por ejemplo, por ser retratos de personajes), o cabe fácilmente presuponer que fueron obtenidos en el lugar de origen del actor principal, que casi siempre es España.

La procedencia geográfica de las tomas se reparte de la siguiente manera: a) La llustración Española y Americana, 37 en Cuba, 16 en España, y 2 en Estados Unidos; b) Blanco y $\mathrm{Ne}$ gro, 55 en España, 37 en Cuba y 10 en Estados Unidos; c) Nuevo Mundo, 44 en España, 20 en Cuba y 1 en la colonia portuguesa de Cabo Verde, lugar del que zarpó la escuadra española destruida en Santiago de Cuba. El cómputo general indica que la mayor parte de las imágenes que ilustraban esta contienda fueron realizadas en España, lo que marca un notable distanciamiento espacial entre los hechos y su referente gráfico.

La identificación temporal presenta índices muy bajos; es mayor en Blanco y Negro (36 de las 139 fotografías), seguida de La llustración Española y Americana (10 de las 73 fotos) y Nuevo Mundo (sólo en 3 de las 133 imágenes). Esto induce razonablemente a pensar que en muchos casos pudieran ser imágenes de archivo.

\section{Actantes: geopolitica y roles}

Al tratarse de una contienda sustanciada en el escenario naval, Nuevo Mundo publicó fotografías de todos los buques de las escuadras española y norteamericana, ello explica el predominio en sus informaciones de este tipo de imágenes (83 de las 133 totales). Por contra, 
(83 de las 133 totales). Por contra, tanto en La llustración (52 de 73) como en Blanco y Negro (94 de 139) las fotografías dan protagonismo esencial a los actores humanos. Los datos de las fotografías analizadas correspondientes a este atributo aparecen reflejados en la Tabla II. En su interpretación debe tenerse en cuenta el hecho de que en una misma fotografía pueden aparecer varios personajes como protagonistas.

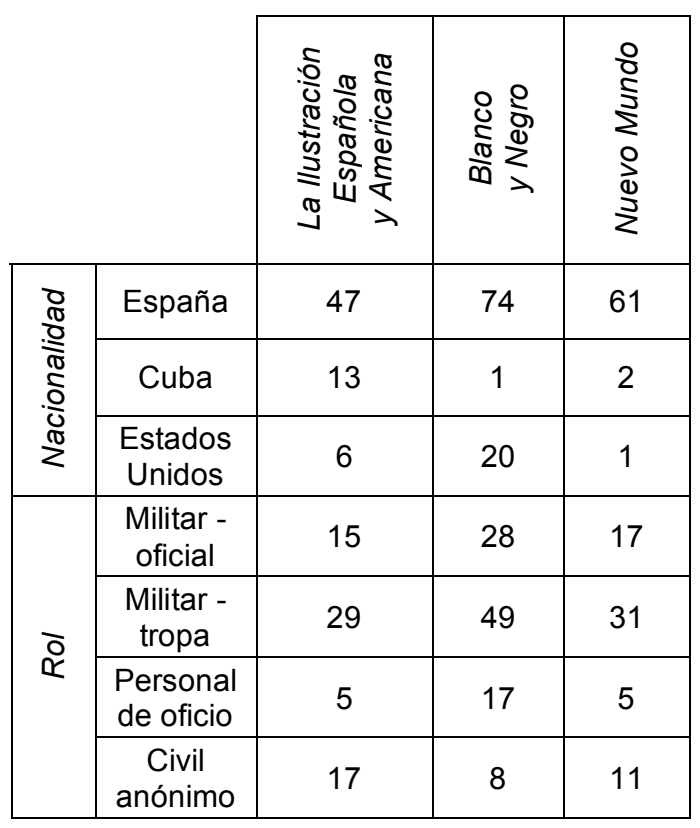

Tabla II: distribución geopolítica y los roles de los personajes humanos

En referencia a la tabla anterior, se observa que la mayor parte de las fotos están protagonizadas por militares, miembros de tropa y oficiales. Se publican fotografías de los personajes más destacados de ambos bandos, como los generales Linares, Pando, Montero, Blanco, Vara del Rey o los americanos W.R. Shafter y Roosevelt, y los mandos de la escuadra española que resultó destruída: Cervera, Díaz Morey, Villaamil, Concas o Lazaga. Como nota curiosa, Blanco y Negro publicó fotos del corresponsal del diario The Journal en el campamento norteamericano de Tampa y su esposa, única mujer que aparece en las fotografías publicadas.

\section{Acciones de guerra, víctimas o heridos}

Un rasgo revelador es que entre las fotografías analizadas no figura ninguna de cadáveres. Las únicas fotos que muestran aspectos dramáticos, con soldados heridos o convalecientes, son las de la llegada a España de las tropas repatriadas desde Cuba: 10 publicadas en La llustración, 5 en Blanco y Negro y 7 en Nuevo Mundo, y cuya publicación causó un gran impacto público.
Sólo en dos tomas, aparecidas en Blanco y Negro y realizadas por fotógrafos norteamericanos tras el desembarco del Ejército de su país en Cuba, el pie de foto indica que se trata de avances de tropas o con fuego real, aunque pueda resultar dudoso porque no se aprecia humo o disparos. Es mayor el número de fotos de campamentos o formaciones militares, pero no obtenidas durante el desarrollo de batallas.

\section{B) Codificación fotográfica}

Encuadres. Considerando tres tipos de encuadre básicos (general, medio y corto), los datos obtenidos son categóricos: de las 354 fotografías que integran la muestra, 222 presentan encuadre general, 77 encuadre medio y 46 corto. El peso mayoritario del plano general se da en las tres revistas objeto de estudio y en muchos casos se corresponde con la técnica paisajística característica de la fotografía del siglo XIX. Los paisajes se enfatizan sobre las personas, que en muchas tomas se ven como simples elementos decorativos dentro de un marco escénico muy abierto.

Acción/Estatismo. La mayor parte de las fotografías (290 de las 354 ) registran personajes en posiciones estáticas, muchas de ellas a modo de "pose" dispuesta por el fotógrafo, lo que se da por igual en las tres publicaciones analizadas. Debe tenerse en cuenta que las posibilidades técnicas de la fotografía de la época, con largas exposiciones y cámaras sin velocidad de obturación, dificultaban la congelación del movimiento. Por otro lado, y relacionado con lo anterior, se mantenía una tendencia a favor del retrato pictórico basado en la pose, como refleja el dato de que un total de 126 fotografías pertenecen este género. La captación de movimiento aparece sólo en 55 fotografías, siendo éstas acciones de ritmo lento, por ejemplo, tropas andando, no a la carrera.

Gestualidad. En aras a clarificar el análisis, se han establecido seis categorías de contenido gestual, entre las cuales las fotografías analizadas se reparten así: firmeza y disciplina, 97 unidades; belicosidad, 28 unidades; gestualidad indefinida, 26 unidades; tristeza o derrota, 24 unidades; relajo o confianza, 18 unidades; victoria o alegría, 3 unidades. La clasificación de las fotografías dentro de una categoría se realizó teniendo en cuenta que fueran suficientemente próximas o definidas para apreciar los gestos 0 posiciones de las personas.

Escenografía. La escenografía de la muestra analizada responde a varios puntos de referencia ambiental-situacional, algunos de los cuales no son excluyentes entre sí. El desglose de 
datos obtenidos es el siguiente: cotidianeidad o tranquilidad, 43; localización (elementos singulares del ambiente geográfico), 83; identificación indumentaria de los personajes (rango, estatus...), 102; destrucción o derrota, 25.

Dentro de los rasgos escenográficos, el ambiente de desolación o drama presenta una muy escasa relevancia cuantitativa. No hay fotografías con escenas de incendios, humaredas o combates cuerpo a cuerpo, sino sobre las secuelas no humanas de estos hechos, como las imágenes publicadas en Blanco y Negro de los barcos de la flota española destruidos y de los soldados evacuados a nuestro país.

\section{C) Maquetación}

Tamaño: columnas y páginas. La consideración del tamaño en página otorgado a cualquier elemento es un índice fundamental de su importancia informativa. En tal sentido, las unidades fotográficas que componen la muestra se han clasificado por el número de columnas de la pauta a que van compuestas. Los valores obtenidos en cómputo general de las tres revistas son: 72 fotografías compuestas al ancho de página, 52 fotografías a $3 / 4$ del ancho de página, 134 fotografías a media página, Y 87 fotografías a medida inferior. Proporcionalmente, la revista que más tamaño otorga a las fotografías de la guerra de Cuba fue Blanco y Negro, seguida de La llustración Española y Americana y Nuevo Mundo. Promediando estos resultados, se obtiene que más de la mitad de las imágenes analizadas (221) fueron compuestas en medidas de media página e inferiores, y sólo una escasa proporción a todo el ancho o a página completa, lo que refleja un interés informativo medio-bajo. La mayor parte de las fotografías se maquetan con contornos rectangulares y, en menor, proporción, ovalados. Únicamente en Blanco $y$ Negro se emplean silueteados y recortes, aspectos que anticipan un estilo de maquetación más moderno para la época.

Pies de foto. El acompañamiento con de pie de foto se da en 321 fotografías, es decir, la inmensa mayoría de las publicadas. En todos los casos, se trata de textos breves que aportan información no explícita en la imagen, generalmente sobre la identificación de personajes, lugares, acciones u objetos.

Otros elementos gráficos. La mayor parte de las fotografías analizadas están compuestas en página junto a otros elementos gráficos. La utilización cuantitativa de los mismos se distribuye así en el total de la muestra: otras fotografías, 320 ; orlas, 45; y dibujos, 52 . Esto implica que la mayor parte de las imágenes están acompaña- das en la misma página por fotografías, y en menor proporción por orlas y dibujos. Este último aspecto se aprecia la pervivencia de usos estéticos tradicionales de la prensa ilustrada, aún vigentes a finales del siglo $\mathrm{XIX}$, presentes en Blanco y Negro y La llustración y apenas en Nuevo Mundo.

3.2. Análisis estructural: asociación, equivalencia o exclusión entre ítems de contenido

\section{Imagen del conflicto: Gestualidad, encuadres y escenografía}

Las fotografías analizadas transmiten una realidad visual de la guerra de Cuba que está muy condicionada por los rasgos gestuales y escénicos, así como por los tipos de encuadres fotográficos donde se enmarcan los personajes, y que varía según el rol, el tipo de acción que reflejen o la identidad geopolítica de los mismos. La imbricación de todos estos indicadores permite observar las siguientes correlaciones:

- En lógica analogía con la naturaleza del tema, los rasgos gestuales más significativos son la belicosidad y la disciplina o firmeza, que se reflejan mayoritariamente en las fotografías de personajes con rol militar, tanto españoles como norteamericanos, con respecto a los de otros roles. Asimismo, las imágenes de formaciones de soldados norteamericanos se observa mayor sensación de orden y un mejor equipamiento que en las españolas, aspecto no muy alejado de lo que realmente aconteció.

- La imagen del ejército norteamericano que muestran las fotografías en poses y escenarios sugiere orden, disciplina e incluso superioridad, sin ningún aspecto denigratorio, lo que hasta cierto punto es paradójico tratándose del bando enemigo. Por el contrario, la derrota, el cansancio y el abatimiento son rasgos que sólo aparecen reflejados en las imágenes de los repatriados españoles tras la capitulación, evidencia de la cruda realidad del bando vencido que no se ocultó a la opinión pública.

- Las tomas que registran algún tipo de acción están protagonizadas por actores de rol militar, básicamente soldados de tropa. En contraste, las fotografías de oficiales están dominadas por el estatismo o la rigidez.

- La mayor parte de las tomas en plano corto corresponden a mandos militares y oficiales, no a soldados de tropa, de los cuales se muestra casi siempre una visión lejana, despersonalizada y grupal, alejada de la mirada del lector, salvo en las fotografías correspon- 
dientes a la llegada de los repatriados, a los que la cámara se "acerca" más.

- Aún en los momentos álgidos del conflicto, cuando se desarrollaban los episodios más cruentos, las fotografías de los escenarios donde tenían lugar los combates muestran un ambiente de tranquilidad y cotidianeidad, aunque los textos informativos a los que acompañan sí narran acciones bélicas en términos dramáticos. Esto sólo puede explicarse por el hecho de que las fotos fueron tomadas antes de las acciones de guerra, es decir, eran tomas de archivo. Se produce, por tanto, un cruce de mensajes opuestos entre el texto y la fotografía. En este sentido, es sabido que en pocos combates de esta guerra hubo presencia de fotógrafos, pero sí se tomaron, como refleja la obra de Tusell, Acosta y Uz (Ibidem), algunos testimonios gráficos de ciertos episodios relevantes: la llegada a Santiago de la escuadra del Almirante Cervera, o la salida de la misma al combate, que no se publicaron en la prensa gráfica española.

\section{Conclusiones}

La interpretación de los anteriores resultados permite inferir varias conclusiones básicas:

1. Los escasos datos documentales que ofrecen las fotografías publicadas en las revistas gráficas españolas sobre la guerra de Cuba, tanto en lo relativo a su autoría como en la determinación de la fecha y el lugar donde fueron obtenidas, revelan un bajo grado de transparencia informativa.

2. Las fotografías ofrecen un gran distanciamiento respecto a los hechos bélicos reales, tanto por no estar obtenidas durante el desarrollo de las acciones de guerra como por el empleo de encuadres excesivamente generales, en los que no es posible apreciar detalles. Predomina en ellas el paisajismo y el retrato, y el estatismo sobre la acción. Se produce, en suma, una recreación artificiosa del conflicto. El fotógrafo aún es más retratista que periodista gráfico.

3. Se muestra una visión estereotipada de los roles, por cuanto otorga al estamento militar en general una imagen de firmeza y seriedad; $y$, dentro del mismo, los mandos transmiten seguridad, estatismo y dominio, en encuadres cortos e individuales, mientras que la tropa tiene una visión de grupo, activa y belicosa.

4. La crueldad de la guerra no aparece reflejada en las fotografías de prensa analizadas. Predominan claramente los rasgos gestuales y escénicos que hablan de coraje y fuerza, pero apenas nada de sufrimiento y dureza, salvo el episodio final de la repatriación de los soldados españoles, que sí fue testimoniada gráficamente con realismo.

5. La maquetación otorga a las fotografías un escaso realce, fundamentalmente debido al tamaño pequeño-medio con que se componen. El auténtico peso informativo recae en los textos que dan fe de los acontecimientos bélicos, ya que las fotografías desempeñan un papel de mero acompañamiento gráfico, pues en su inmensa mayoría no se corresponden con los hechos que ilustran.

\section{Recomendaciones}

A la vista de los resultados y conclusiones obtenidas, se pueden plantear nuevas vías de estudio sobre este tema que contribuirían a profundizar en él y enriquecerlo de forma notable. Pudieran realizarse análisis comparativos entre las publicaciones españolas y sus homólogas norteamericanas de la misma época, o búsquedas de fuentes originales sobre el mismo conflicto en archivos fotográficos españoles para comprobar si fueron o no publicadas en la prensa. Estos y otros posibles cauces de trabajo quedan planteados para futuras investigaciones.

\section{Referencias}

Alonso Erusquin, Manuel (1995). Fotoperiodismo: formas y códigos. Madrid: Síntesis, 1995.

Bardin , Lawrence (2002). El análisis de contenido. Madrid: Akal, 2002.

Martín Aguado, José A.; Armetia Vizuete, José I. (1995). Tecnología de la Información Escrita. Madrid: Síntesis, 1995.

Rodríguez Merchán, Eduardo y Gómez Alonso, Rafael (2003). Una historia de la fotografía en la prensa. // Caballo Ardila, Diego (cord.). Fotoperiodismo y edición: historia y límites jurídicos. Madrid, Universitas, 2003. 17-96.

Sousa, José P. (2003). Historia crítica del fotoperiodismo occidental. Sevilla: Comunicación Social Ediciones y Publicaciones, 2003.

Tusell, Javier; Acosta, Eliades; Uz, Enrique de la (2005). Fotografías de la guerra de Cuba. Valencia: Pentagraf D.L., 2005.

Valle Gastaminza, Félix del (1999). El análisis documental de la fotografía. // Félix del Valle Gastaminza (ed.). Documentación Fotográfica. Madrid: Síntesis, 1999. 113131.

Vilcles, Lorenzo (1987). Teoría de la imagen periodística, Barcelona, Paidós, 1987. 